\title{
LOS OJOS FEMENINOS EN LA
}

\section{PUBLICIDAD AUDIOVISUAL}

\section{Estrella Martínez Rodrigo}

\author{
Profesora Doctora \\ Facultad de Comunicación y Documentación. Universidad de \\ Granada. Edificio Colegio Máximo. Campus de Cartuja s/n. \\ 18071, Granada (España) - Tlfn: (+34) 958241963 - Email: \\ emrodrigodugr.es - Web: http://fcd.ugr.es
}

\section{Resumen}

Son numerosos los estudios realizados tanto en Estados Unidos como en Europa sobre el tratamiento de la imagen de la mujer en la publicidad televisiva. En todos ellos se llama la atención sobre la relevancia concedida a su aspecto físico, del que se ha destacado, sobre todo, la exaltación de su belleza, su esbeltez y su sensualidad, con predominio de una u otra de estas características según el caso. No se encuentran, en cambio, estudios específicos sobre las características particulares de su rostro: rasgos étnicos, color o longitud del cabello, dimensiones o líneas predominantes, etc. En este artículo se aborda por primera vez el estudio del color de los ojos (claros u oscuros) del personaje femenino en la publicidad televisiva y su relevancia en los spots. La investigación realizada no se centra sólo en los valores absolutos encontrados, sino en su relación con otros datos, en concreto, con la clase de productos que anuncia la mujer, con los tipos de actividad que desempeña en los spots y con las personas que le acompañan en cada caso.

\section{Palabras clave}

Mujer, publicidad, ojos, televisión, lenguaje audiovisual, figura femenina, efectos de la publicidad

Key Words

Woman, advertising, eyes, television, audiovisual language, femmenine body, advertising effects

\section{Abstract}

There are many studies on the woman image in television advertisement, both in the United States

and Europe. All these studies

focused on the importance of her physical appearance, especially her beauty, her slenderness and sensuali-

ty, depending on its significance within the product. There are not, however, specific studies on her face

particular characteristics: ethnic nuances, hair length or colour, main sizes or lines, etc. In this article it is

examined, for the first time, the colour of the eye (light or dark) of

the feminine figure of television spots and its relevance in the advertisement. This investigation does not only concentrate on absolute values

but also in their relationship with other data, particularly with the sort of products that the woman adverts, the kind of role she develops in the spot and the people who is with her in each case. 


\section{Introducción}

A lo largo de la historia de la publicidad, se ha tratado abundantemente la presencia de la mujer y sus características personales, relacionadas fundamentalmente con sus cualidades físicas y con los roles desempeñados. En este trabajo se trata analizar un rasgo físico del personaje femenino que hemos encontrado en los spots televisivos seleccionados, y que no ha sido tratado hasta ahora en los Women Studies. La investigación se centra en el color de los ojos de la mujer. Entendemos que no es casual este dato, sino que se elije a una mujer de ojos claros u oscuros en función de la imagen de ella que se quiere comunicar y de lo que esta cualidad es capaz de transmitir a los espectadores, como valor añadido del producto publicitado.

\section{Objetivos}

El objetivo de esta investigación se centra en intentar mostrar los motivos del creador publicitario para elegir mayoritariamente como personaje de los spots televisivos a mujeres de ojos claros o de ojos oscuros, en relación con el producto que anuncian, con la tarea que realizan y con el tipo de personas que la acompañan en cada caso.

\section{Metodología}

Hemos seguido en esta investigación la metodología del análisis de contenido, combinando las técnicas de carácter cualitativo y cuantitativo, utilizando el programa estadístico SPSS. Se han analizado 468 anuncios televisivos diferentes en los que apareciera algún personaje femenino, emitidos durante el prime time en TVE $1 \mathrm{y}$ 2, Antena 3 y Telecinco, a lo largo de 6 meses seguidos. Las categorías y variables utilizadas han sido las siguientes, que indicamos por orden de frecuencia total: color de ojos (oscuros, claros), productos (cosmética, alimentación, hogar, bebidas, salud, coches, comunicación, revistas, ropa, finanzas, infantiles, hipermercados, instituciones, ocio y solidaridad), tareas desempeñadas (ocio, exhibición, otra tarea distinta a las aquí mencionadas, tareas del hogar, arreglo personal, otro trabajo distinto a los mencionados, trabajo clásico, compra, deporte, trabajo de dirección, trabajo científico) y personas que acompañan a la mujer (nadie, hijo niño, varón, marido, amiga, amigos, colegas, gente, hijo bebé, mujer ajena a la familia, hijo adolescente, animales, madre, hijo joven, hermanos, hijo maduro). La combinación de dichas variables ha dado lugar a los resulta- 


\section{La belleza femenina en la publicidad}

Al hablar de belleza, hay que tener en cuenta en primer lugar que, en la sociedad de consumo, la noción de lo bello ha ido perdiendo su carácter trascendental para reducirse a lo más material y tangible. Así, hace ya tres décadas declaraba Baudrillard (1974) que ser bella ya no es un efecto de la naturaleza ni una valoración de las cualidades morales, es la cualidad fundamental, imperativa de aquellas que cuidan su rostro y su línea como si fuera su alma.

Por eso afirmaba en aquel entonces Escola (1978) que la publicidad valora en demasía todo lo referente al aspecto externo (fortaleza en el caso del hombre, belleza en el caso de la mujer) en detrimento de cualquier tipo de cualidad intelectual.

Antes de los años 80 la definición de la mujer publicitaria se hace exclusivamente a partir de dos factores: su inserción en el hogar, que ya hemos visto, y su juventud manifestada a través de su belleza. Las mujeres representadas en la publicidad son siempre jóvenes y atractivas; en cambio, rara vez aparecen en los anuncios como personas competentes o inteligentes. La inteligencia se presenta como un rasgo masculino y, en consecuencia, las mujeres inteligentes son poco femeninas o no les gustan a los hombres. En efecto, para la publicidad tradicional, ser mujer significa ser joven y tener un cuerpo modélico, con rasgos que están en función del otro sexo y cuyos ejes centrales son el amor, la fascinación y la seducción. Pero es interesante llamar la atención sobre la observación que ya en esos años hace Ceulemans (1979), cuando dice que, a la imagen familiar de la mujer preocupada por su aspecto para atraer la atención del hombre y alcanzar el éxito social.

"La publicidad ha añadido la imagen de la mujer narcisista, que es igualmente sensual y consciente de su belleza femenina, pero que se preocupa únicamente de sus sentimientos personales sobre sí misma" (Ceulemans, 1979).

Importa llamar la atención sobre este aspecto, porque se ha considerado como una diferencia significativa de la publicidad de los 90 con respecto a la de décadas anteriores.

La belleza se asocia, por tanto, al ideal de mujer con poder y status, respetada $y$ autónoma. Lógicamente, la idea de belleza está condicionada por la sociedad y por la moda: hablar de belleza es hablar tanto de un contexto cultural como de un código formal. Pero lo cierto es que la publicidad ha potenciado el cuidado de la fachada hasta el punto de crear en el consumidor el síndrome de belleza; es decir, la obsesión por adecuarse a la moda imperante. Pero esa preocupación estaba ya presente hace 
más de dos décadas. Y según José Luis León (1996), ésta será una constante de la publicidad desde sus comienzos hasta nuestros días. En el caso de la mujer, la belleza es probablemente la cualidad que la hace más valorable, la que se tiene en cuenta en primer lugar, la que se hace más destacable socialmente.

Así pues, en relación con la belleza, segunda área importante de la representación femenina en publicidad señalada por los Women Studies, podemos señalar que un efecto inmediato es la idealización de la edad juvenil. Y esto incluye tanto lo que se refiere a la piel como a la silueta, $y$, sobre todo, a los estilos de vida. En cuanto a los modelos de belleza, a diferencia del cine y de otras artes que llegan a presentar como atractivas a mujeres cuyo aspecto físico se desvía de los modelos estándar, en publicidad los cánones de belleza tienden a uniformarse.

Como es lógico, de la excesiva exhibición de la belleza se derivan ciertos efectos negativos; J.L. León (1996) destaca algunos que considera de especial trascendencia, como inseguridad en la mujer sobre su apariencia física, que puede conducirle a un estado de ansiedad; el descontento masculino hacia sus consortes, que, como es lógico, no suelen alcanzan el canon de belleza impuesto por los medios; la obsesión por adelgazar mediante prácticas dietéticas que le llevan, en muchos casos a la anorexia; la percepción fragmentada de cada mujer, en la que se valoran, sobre todo, sus características corporales, en detrimento de otros valores de la persona, objetivamente más relevantes. Una clara disminución de la autoestima es el resultado detectado también por Richins (1981), que ha mostrado cómo la mujer media utiliza las imágenes idealizadas de las modelos publicitarias para evaluarse a sí misma. En un estudio comparativo entre la idealización corporal publicitaria y la estética de la vida real, concluye que los anuncios estudiados conducían a una minusvaloración del físico normal, tanto propio $\mathrm{CO}^{-}$ mo ajeno, aunque esto era compatible con la aceptación del producto anunciado y del propio anuncio. Este proceso podría ser incluso más grave en el caso de las mujeres españolas que en las de otros países occidentales, pues la valoración que hacen de su apariencia personal resulta inferior: según Iglesias de Ussel (1992), se ha calculado casi un $10 \%$ la subestimación femenina comparada entre España y Estados Unidos.

Sobre la belleza, dice $\mathrm{M}^{\mathrm{a}}$ Ángeles Durán (2002: 10) las mujeres siguen acumulando muchos papeles, entre ellos el de ser atractivas y jóvenes, y tendrán que conseguir poco a poco librarse de esas obligaciones, por lo menos quienes no deseen definirse socialmente por esos papeles.

Pero la consecuencia negativa más inquietante de este hecho es la que J. L. León (1996) ha denominado 'selección socioestética de la especie', que conlleva una discriminación profesional cada vez mayor 
para quienes no alcancen las exigencias del canon estético presentado por la publicidad y los medios en general.

\section{El significado de los ojos en la publicidad}

La importancia de los ojos en la publicidad, y en concreto, en los spots televisivos, procede de la intencionalidad de mostrarlos. En efecto, son unos órganos tan pequeños en el conjunto de la persona, que se requiere un primer plano o un plano detalle para que el receptor los perciba. Por tanto, si se muestran se hace con algún objetivo.

En este estudio hemos distinguido entre ojos claros y ojos oscuros, prescindiendo del color más preciso, puesto que esa distinción es la que nos parece relevante para el publicitario. De todos modos, hay que señalar, que en el $8,4 \%$ de los spots no se ve el color de los ojos de la mujer.

Son los ojos oscuros los que predominan sobre los claros, que sólo aparecen la tercera parte de las veces que aquellos.

Llama la atención ese predominio de los ojos oscuros, porque en nuestro imaginario está bastante relacionada la idea de belleza y juventud con el cabello rubio y los ojos claros. En cambio, quizá mediante los ojos oscuros se consigue una mayor identificación con el prototipo de mujer española. Nos ha parecido interesante investigar la relación que el color de los ojos de la mujer puede tener con el producto que anuncia, con las personas que le acompañan y con la tarea que realiza.

Cuadro $n^{o} 1$. Color de los ojos

\begin{tabular}{|l|l|c|c|c|}
\hline \multicolumn{5}{|c|}{ COLOR DE LOS OJOS } \\
\hline \multicolumn{2}{|c|}{} & Frec. & $\%$ & $\begin{array}{c}\% \\
\text { válido }\end{array}$ \\
\hline \multirow{2}{*}{} & oscuros & 279 & 59,6 & 75,6 \\
\cline { 2 - 5 } & claros & 90 & 19,2 & 24,4 \\
\cline { 2 - 5 } & Total & 369 & 78,8 & 100,0 \\
\hline Perdidos & Sistema & 99 & 21,2 & \\
\hline Total & & 468 & 100,0 & \\
\hline
\end{tabular}

Fuente: Elaboración propia

\subsection{Color de ojos $y$ producto anunciado}

Analizaremos en primer lugar la relación entre el color de ojos de la mujer y el producto que anuncia. En nuestro estudio hemos hallado cinco clases de productos de especial relevancia: cosméticos, alimentos, productos del hogar, bebidas y productos de salud; el resto aparece con una frecuencia inferior al 5\%, que no puede considerarse significativa. 


\section{Gráfico no 1: Color de ojos y producto}

OJOS*PRODUCTO
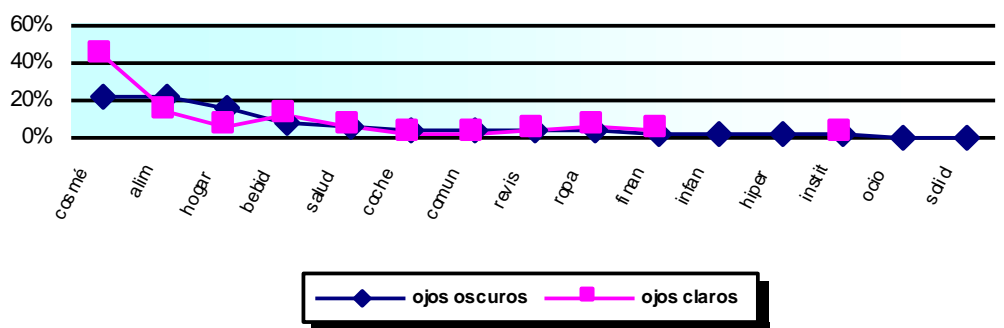

Fuente: Elaboración propia

La mujer de ojos oscuros anuncia cualquier producto, y su presencia se reparte principalmente entre los anunciados con más frecuencia: alimentación (22,6\%) -sobre todo, general-, cosmética $(21,9 \%) \mathrm{y}$, con mucha menos frecuencia, bebidas $(7,9 \%)$, especialmente los refrescos.

La presencia de la mujer de ojos claros se reparte prioritariamente entre productos de cosmética $(43,3 \%)$-especialmente para el rostro-, donde la encontramos el doble de veces que a la mujer de ojos oscuros; mucho menos la vemos anunciando productos de alimentación (14,4\%) -nunca en lácteos ni repostería- y en bebidas (12,2\%), donde también supera a la mujer de ojos oscuros. La vemos una sola vez en anuncios institucionales y de comunicación, y nunca en productos infantiles, ni de hipermercados, ni de ocio, ni de solidaridad. Es decir, en realidad sólo cuenta con una presencia de interés en la mitad de los productos que hemos registrado, y en los demás lo hace con una frecuencia inferior al 5\%.

Si cambiamos el punto de vista y nos fijamos en los productos, todos ellos recurren con mayor frecuencia a la mujer de ojos oscuros; los que más nos muestran a la de ojos claros son los anuncios de cosméticos (39,9\%) y los de bebidas (33,3\%).

En resumen, podemos decir que la publicidad considera a la mujer de ojos oscuros como apta para anunciar cualquier tipo de producto, aunque resulta especialmente eficaz para los de alimentación y cosmética. La mujer de ojos claros, en cambio, está presente en una gama de productos más restringida, aunque aparece con mucha más frecuencia en los relativos a la cosmética facial y a las bebidas. Y es precisamente la publicidad de cosmética la que con más frecuencia se adorna con otra nota femenina: una voz de mujer acompañando una música sin letra, que hace aumentar el 
glamour del producto y de la situación que se narra (Martínez Rodrigo, 2004).

Un apunte que consideramos interesante es que el color oscuro, por su asociación más marcada hacia la madurez, es el más apropiado para la mujer que anuncia productos infantiles, pues su imagen se aproxima más al estereotipo de madre de familia socialmente asentado.

\subsection{Color de ojos $y$ actividad realizada por la mujer}

Analizaremos a continuación la relación que se ha encontrado entre el color de ojos de la mujer y la tarea que realiza en el spot. Hay que señalar que en nuestro estudio las tareas realizadas por la mujer son mayoritariamente no profesionales, frente a las profesionales, ninguna de las cuales es relevante.

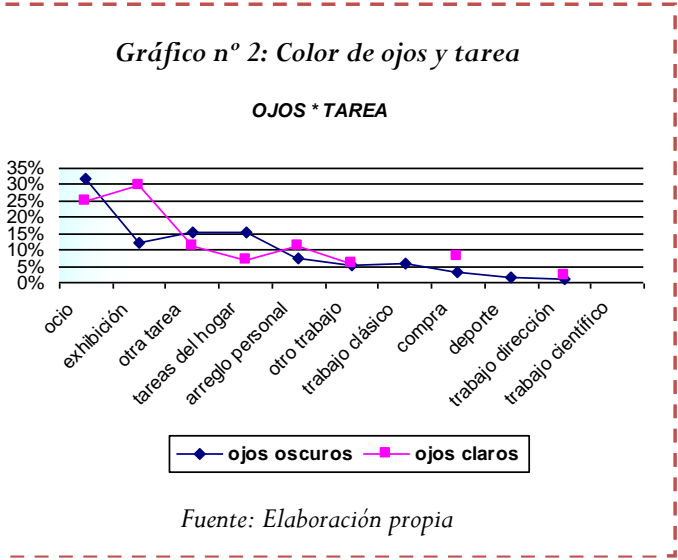

La mujer de ojos oscuros predomina en cualquier actividad. Se dedica sobre todo al ocio $(31,9 \%)$ y después a tareas del hogar o a otras tareas diversas $(15,6 \%)$, por igual; luego, la vemos tanto realizando algún trabajo profesional como exhibiéndose (12\%); sólo después se ocupa del arreglo personal.

$\mathrm{Si}$, como en el apartado anterior, cambiamos el punto de vista y pasamos a fijamos en qué tareas los publicitarios recurren a una u otra mujer, observamos que en todas las tareas no profesionales acuden más a la mujer de ojos oscuros. Aumenta la de ojos claros cuando se trata de exhibirse (43,8\%) o de comprar, aunque esta actividad no es relevante. Llama la atención lo poco frecuente que es esta mujer en las tareas del hogar $(12,8 \%)$.

Por otra parte, hemos observado que en los trabajos profesionales hay un índice más alto de mujeres con ojos oscuros $(82,5 \%)$ que en los no profesionales, y en un trabajo profesional clásico no encontramos ni una sola una mujer de ojos claros. Hay que precisar que en el trabajo científico nunca se puede apreciar el color de los ojos, por estar mirando un microscopio o algo por el estilo.

En síntesis, el personaje femenino de ojos oscuros resulta ser más polivalente: realiza todo tipo de actividades, aunque muestra predilección por las referidas al ocio y, después, al hogar o a otras tareas. Por el contrario, el personaje femenino de ojos claros reduce mucho más su espectro: fundamentalmente se exhibe (es clara su asociación con la juventud, siempre idealizada en la publicidad) y, junto con el ocio, encuentra más tiempo que la otra para el arreglo personal o tareas indefinidas. 
En la esfera de lo profesional, la mujer de ojos oscuros aparece con mayor frecuencia: parece asociarse a este color un mayor sentido de la responsabilidad y la laboriosidad.

En cambio, la mujer de ojos claros realiza tareas no profesionales el $92 \%$ de las veces: fundamentalmente se exhibe (29,5\%) o se encuentra en actividades de ocio (25,0\%); en tercer lugar se dedica por igual al arreglo personal o a otra tarea no definida $(11,4 \%)$.

\subsection{Color de ojos $y$ compañía que le rodea}

Por último, pasamos a analizar la relación entre el color de los ojos de la mujer y el tipo de personas que le acompañan. Según nuestro estudio, la mujer está acompañada principalmente por personas ajenas a su familia, luego la encontramos sola y después con su familia. A este respecto, es interesante consultar el estudio de Gaona \& Martínez (2009) sobre determinadas campañas de publicidad.

\section{Gráfico $n^{\circ}$ 3: Color de ojos y compañía}

COLOR DE OJOS * COMPAÑIA

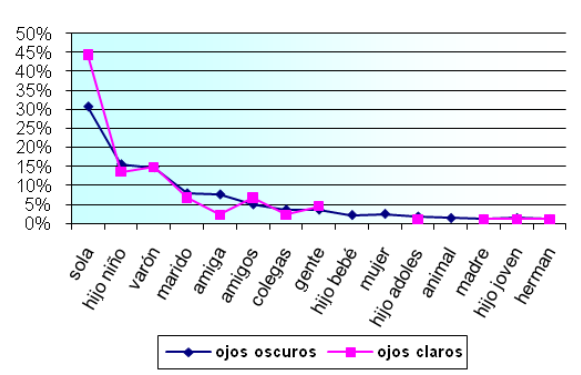

Fuente: Elaboración propia
A la de ojos oscuros la encontramos con cualquier tipo de compañía; en primer lugar con personas ajenas a su familia $(38,5 \%)$, sobre todo con un varón $(14,7 \%)$ o con una amiga $(7,6 \%)$. Luego, la vemos con su familia (30,9\%), especialmente con algún hijo niño $(15,5 \%)$ y con su marido $(7,9 \%)$. Casi con la misma frecuencia que con su familia la encontramos sola $(30,6 \%)$. En realidad, la mujer de ojos oscuros se reparte prioritariamente entre las compañías más frecuentes, según el orden general de éstas.

La mujer de ojos claros también se reparte entre las compañías más relevantes, sin mucha diferencia con respecto a la de ojos oscuros, pero aumenta su presencia y supera a la de ojos oscuros, cuando está sola $(44,3 \%)$ y con amigos $(6,8 \%)$. Nunca la encontraremos, en cambio, con un hijo bebé, con otra mujer ni con animales.

A su vez, si nos fijamos en las distintas compañías, cuando la mujer está sola $(31,5 \%)$ o con amigos (30\%) es cuando más aumentan los ojos claros frente a los oscuros sin predominar nunca sobre ellos. Este color de ojos queda poco asociado a la compañía familiar.

A modo de resumen, la mujer de ojos oscuros aparece con todo tipo de compañías, pero su presencia resulta especialmente relevante en el entorno familiar: con algún hijo varón o con su marido. Por el contrario, la mujer de ojos claros se nos muestra con especial significación o bien sola o con amigos. Aunque sólo con carácter provisio- 
nal, se acumulan indicios para identificar un nuevo estereotipo femenino en la publicidad, esta vez relacionado con una cualidad cromática: la claridad de ojos se asocia más a las relaciones sociales o al narcisismo de la mujer, mientras que la oscuridad de aquellos se asocia al ámbito familiar o profesional.

\section{Conclusiones}

A partir de los comentarios a los resultados parciales que se han ido adelantando a lo largo del análisis, podríamos englobar las conclusiones de nuestra investigación en las siguientes:

- Predomina claramente el personaje femenino publicitario de ojos oscuros. Esta cualidad queda asociada a productos de alimentación del hogar (especialmente los infantiles), al ámbito familiar, y a la madurez y al sentido de responsabilidad en el trabajo. En realidad, viene a representar el estereotipo de la mujer real y más frecuente en la sociedad española.

- La mujer de ojos claros es minoritaria, pero ocupa prácticamente todos los anuncios de cosmética. Se encuentra fundamentalmente sola y no suele realizar ningún trabajo, sino que se dedica a su exhibición narcisista. Su compañía, cuando la tiene, se reduce a sus amigos, en un ambiente de ocio. Este color de ojos añade, pues, unas connotaciones de idealización de la belleza femenina, más alejada de las situaciones habituales de la vida ordinaria.

\section{Referencias}

BAUDRILLARD, J. (1979). La société de consommation, Denoël. Paris.

CEULEMANS, M. \& FAUCONNIER, G.(1979). Image, rôle et condition sociale de la femme dans les médias. UNESCO/Études et documents d'information, n. 84. Paris.

DURÁN, Ma A. (2002). Entrevista en Domingos de $A B C$, n. 159, 29 septiembre 2002, p. 10, Madrid.

ESCOLA, C., TAMAYO, M., ZALLO, I. (1978). "La imagen de la mujer a través de la publicidad en las revistas españolas", Papers, 8, 135-148.
GAONA, C. \& MARTÍNEZ PASTOR, E. (2009).

"Análisis de género de las campañas de publicidad de la Dirección General de Tráfico”, Icono 14, n. 13.

IGLESIAS DE USSEL, J. (1992). "El culto a la belleza”, en Amando De Miguel (ed.), La sociedad española, 1992-1993, Alianza: Madrid, 1992, pp. 319330.

LEÓN, J. L. (1996). Los efectos de la publicidad. Ariel: Barcelona.

MARTÍNEZ RODRIGO, S. (2004). "Música y mujeres en la publicidad televisiva”, Comunicar, $n^{\circ} 23$. 
RICHINS, M. L. (1981). "Social comparison and the Idealized Images of Advertising”, Journal of Consumer
Research, junio, 71-83.

\section{Cita de este artículo}

MARTÍNEZ RODRIGO, E. (2010) Los ojos femeninos en la publicidad audiovisual. Revista Icono14 [en línea] 1 de Octubre de 2010, Año 8, Vol. Especial. pp. 257-266. Recuperado (Fecha de acceso), de http://www.icono14.net 